\title{
EFEITOS DA ÉPOCA DE SUSPENSÃO DA FERTIRRIGAÇÃO E NÍVEIS DE REPOSIÇÃO DE ÁGUA NA CULTURA DO CRISÂNTEMO (Dendranthema grandiflora) ${ }^{1}$
}

\author{
JOELMA REZENDE DURÃO PEREIRA ${ }^{2}$ \\ JACINTO DE ASSUNÇÃO CARVALHO ${ }^{3}$ \\ PATRÍCIA DUARTE DE OLIVEIRA PAIVA ${ }^{4}$ \\ ÉLIO LEMOS DA SILVA \\ VALDEMAR FAQUIN ${ }^{5}$
}

\begin{abstract}
RESUMO - Conduziu-se um experimento na Universidade Federal de Lavras, MG, com os objetivos de estudar o comportamento da cultura do crisântemo, cultivado em estufa, referentes a três épocas de suspensão da fertirrigação e avaliar os efeitos de diferentes níveis de déficits hídricos sobre a planta e a qualidade do produto final. O delineamento foi inteiramente casualizado em esquema fatorial, com quatro níveis de reposição da água consumida $(100,80,60$ e $40 \%)$ e três épocas de suspensão da fertirrigação (20, 40 e $60 \%$ das inflorescências abertas) com seis repetições. Os parâmetros analisados foram: comprimento e diâmetro da haste,
\end{abstract}

\begin{abstract}
número de folhas, número de inflorescência, diâmetro das inflorescências, matérias fresca e seca das raízes e classes de qualidade. Com a reposição de $100 \%$ da água consumida, obtiveram-se os melhores resultados, exceto para a altura da haste, em que os melhores resultados foram obtidos com reposição de 100 e $80 \%$ da água consumida. As épocas de suspensão da fertirrigação influenciaram apenas o diâmetro das inflorescências, contatando-se que as maiores inflorescências foram obtidas suspendendo a fertirrigação quando $60 \%$ das inflorescências apresentavam abertas. Observou-se para as matérias fresca e seca efeito não-significativo tanto dos tratamentos aplicados.
\end{abstract}

TERMOS PARA INDEXAÇÃO: Crisântemo, déficit hídrico, adubação.

\section{FERTIGATION INTERRUPTION TIME AND WATER REPLACEMENT LEVELS EFFECTS OVER THE CULTURE OF CHRYSANTHEMUM (Dendranthema grandiflora)}

\begin{abstract}
An experiment was carried out at the Universidade Federal de Lavras, MG, aiming to study the behavior of chrysanthemum cultivated in a greenhouse under three different fertigation interruption time, and to evaluate the effects of different levels of water deficits on the plant and the final product quality. A completely randomized experimental design in a factorial outline, with four water consumed replacement levels $(100,80,60$ and, $40 \%)$ and three fertigation interruption time (20, 40 and $60 \%$ of open inflorescences) with six replications was wed.
\end{abstract}

The analyzed parameters were: stem length and diameter, leaves number, inflorescence number, inflorescence diameter, dry and wet roots matter, and quality classes. The best results were obtained with a $100 \%$ of water replacement, exception for stem length where the best results were obtained with a 100 and $80 \%$ of water replacement. Fertigation interruption time just influenced inflorescence diameter. The largest inflorescence diameter was obtained when fertigation was interrupted after $60 \%$ of inflorescence opening. Dry and wet root matter showed no significant response to the applied treatments.

1. Parte da dissertação de Mestrado apresentada pelo primeiro autor à UNIVERSIDADE FEDERAL DE LAVRAS/UFLA, Caixa Postal 37 - 37200-000 - Lavras, MG, com apoio da FAPEMIG.

2. Engenheiro Agrícola, M.Sc. em Irrigação e Drenagem, Departamento de Engenharia/UFLA, (35) 3822 1507, jrpereira@navinet.com.br.

3. Professor Adjunto do Departamento de Engenharia/UFLA.

4. Professor Adjunto do Departamento de Agricultura/UFLA.

5. Professor do Departamento de Ciência do Solo/UFLA. 


\section{INTRODUÇÃO}

O setor da floricultura no Brasil aponta para uma das melhores alternativas para quem busca investimento na agricultura. Isso porque demanda pouca área e o ciclo de produção, dependendo da cultura, é geralmente curto, o que permite giro rápido do capital (Matsunaga, 1995). Como planta ornamental de grande destaque, o cultivo do crisântemo em vaso ocupa o primeiro lugar no mercado interno, respondendo por aproximadamente $80 \%$ do total das flores comercializadas nessa forma (Fernandes, 1996). No entanto, as plantas ornamentais, de forma geral, são bastante susceptíveis às deficiências hídricas, principalmente às grandes variações do nível de água no solo, refletindo-se num desenvolvimento precário e desuniforme do produto final. A irrigação de plantas ornamentais é uma área incipiente. Poucas foram as pesquisas desenvolvidas, podendo-se citar, dentre essas, Fernandes (1996), que estudou crisântemos da variedade Shuriky; Furlan (1996), que analisou a cultivar Puritan. Apesar da irrigação e também da fertirrigação consistirem em técnicas amplamente utilizadas na cultura do crisântemo, são escassas as informações sobre a época e frequiência de aplicação, seja para cultivo a céu aberto, seja para cultivo protegido. No estudo realizado por Lima (1987) verificam-se variações nas dosagens dos nutrientes, no número de parcelamentos e nas épocas de aplicação dos fertilizantes. Com relação à época de suspensão da adubação, nota-se que não há um consenso entre os produtores. Assim sendo, com este trabalho teve-se como objetivos estudar o comportamento da cultura do crisântemo, cultivado em estufa, referente a três épocas de suspensão da fertirrigação e avaliar os efeitos de diferentes níveis de déficits hídricos sobre a planta e a qualidade do produto final.

\section{MATERIAL E MÉTODOS}

$\mathrm{O}$ atual experimento foi conduzido em casa-devegetação, localizada no Setor de Hidráulica da Universidade Federal de Lavras, em Lavras, MG, cidade localizada a $910 \mathrm{~m}$ de altitude.

A espécie utilizada neste estudo foi a Dendranthema grandiflora (Ramat.) Kitan cultivar White Diamond, cujas mudas foram doadas pela empresa Van Zanten Schoenmaker Chrysanthemum do Brasil, com sede em Santo Antônio de Posse, SP. Foram transplantadas 5 mudas para vasos de polietileno, com as respec- tivas medidas de diâmetro e altura de vaso de $0,123 \mathrm{~m}$ e $0,11 \mathrm{~m}$, com densidade de 10 vasos $/ \mathrm{m}^{2}$, no dia 2 de agosto de 2001.

$\mathrm{O}$ delineamento experimental foi inteiramente casualizado, em esquema fatorial, com quatro níveis de reposição de água $(100 \%, 80 \%, 60 \%$ e $40 \%$ da evapotranspiração diária) e três épocas de suspensão da fertirrigação (20\%, 40\% e $60 \%$ das inflorescências abertas) com seis repetições.

Utilizou-se um sistema de irrigação localizado, por gravidade, para condução do experimento. Esse sistema trabalhou com pressão de $15 \mathrm{kPa}$ e apresentou coeficiente de uniformidade de Christiansen (CUC) de $93 \%$.

O manejo da irrigação foi feito com o auxílio de drenos instalados aleatoriamente em $70 \%$ dos vasos com reposição integral de água. Por esses, obtinha-se o volume de água drenado, um dos fatores usados para realizar o balanço de água no substrato. Os volumes de água aplicados em cada tratamento foram obtidos em função do volume consumido pelos vasos com reposição integral de água. O monitoramento foi feito utilizando-se o balanço de água no substrato, ou seja, no caso de vasos: $\mathrm{Vc}=\mathrm{Vi}-\mathrm{Vd}$, em que "Vc" corresponde ao volume consumido, "Vi", volume utilizado na irrigação (utilizou-se um volume correspondente ao consumido acrescido de 5\% para promover uma pequena percolação) e "Vd", volume drenado.

A suspensão da fertirrigação das plantas foi feita quando: a) $50 \%$ dos vasos, com reposição de $100 \%$ da água consumida, apresentaram $20 \%$ das inflorescências abertas - tratamento C; b) $50 \%$ dos vasos, com reposição de $100 \%$ da água consumida, apresentaram $40 \%$ das inflorescências abertas - tratamento B e; c) $50 \%$ dos vasos, com reposição de $100 \%$ da água consumida, apresentaram $60 \%$ das inflorescências abertas - tratamento A.

O controle fotoperiódico foi feito inserindo-se iluminação artificial com 15 lâmpadas incandescentes de $100 \mathrm{~W}$ instaladas a 1,8 metro de altura e espaçadas de $1,5 \times 1,5$ metro, seguindo a recomendação de Gruszysnki (2000). Essas foram ligadas durante o período noturno por três horas, fornecendo, assim, 15 horas de luz à planta. Essa operação foi feita diariamente durante as duas primeiras semanas. A partir da $3^{\text {a }}$ semana até a colheita, cortinas plásticas de cor preta foram usadas, diminuindo o fotoperíodo da cultura. As cortinas foram fechadas às 16 horas e abertas no dia seguinte às 7 horas, proporcionando, então, 15 horas de escuro diariamente. 
O controle fitossanitário foi realizado utilizando Imidacloprid (70\%) para prevenção da mosca-branca, e Deltamethrin (25\%), para controle da mosca-minadora, aplicados na $6^{\mathrm{a}}$ e $7^{\mathrm{a}}$ semana após transplantio respectivamente.

As adubações seguiram recomendações de LIO (Agnaldo Lio, representante da Van Zanten Schoenmaker Chrysanthemum do Brasil, informação pessoal). Aos 98 dias após o transplantio das mudas, quando $50 \%$ das parcelas do tratamento com reposição de $100 \%$ da água consumida apresentaram $60 \%$ das inflorescências abertas, fez-se a colheita. Após atingirem o ponto de colheita, obtiveram-se o comprimento e diâmetro da haste, número de folhas, número de inflorescência, diâmetro das inflorescências, matérias fresca e seca das raízes. Os vasos de crisântemo foram classificados segundo o padrão do Instituto Brasileiro de Floricultura (IBRAFLOR), (Motos, 2000).

\section{RESULTADOS E DISCUSSÃO}

Observaram-se que os valores máximo e mínimo das temperaturas médias do ar no interior da estufa foram de 36 e $12^{\circ} \mathrm{C}$, respectivamente, estando fora dos limites recomendados para a cultura, que é de 30 e $15^{\circ} \mathrm{C}$, segundo LIO. Isso provavelmente promoveu um atraso no florescimento. O ciclo de produção para a cultivar estudada é de 90 dias. No entanto, houve oito dias de atraso para a colheita dos vasos; o ciclo de produção neste experimento foi de 98 dias. De acordo com Gruszysnki (2000), temperaturas altas e baixas causam atraso no florescimento.

$\mathrm{Na}$ Tabela 1, são observados os resultados da análise de variância para os parâmetros analisados.

Os níveis decrescentes de reposição de água influenciaram negativamente os parâmetros: dimensões da haste, número e diâmetro da inflorescência e número de folhas, havendo diferenças significativas entre os tratamentos, de $1 \%$ e $5 \%$ de probabilidade, conforme teste F. No entanto, a variável época de suspensão da fertirrigação foi significativa apenas para o parâmetro diâmetro de inflorescência. As análises dos parâmetros massas fresca e seca das raízes e classes de qualidade não apresentaram diferenças significativas. Não houve efeito significativo para a interação em nenhum dos parâmetros analisados.

Obtiveram-se tanto com $100 \%$ e $80 \%$ de reposição de água as maiores alturas das hastes (Figura 1).

TABELA 1 - Resumo das análises de variância com os níveis de significâncias das variáveis analisadas.

\begin{tabular}{|c|c|c|c|c|c|c|}
\hline & & \multicolumn{3}{|c|}{ Fontes de Variação } & \multirow{2}{*}{$\begin{array}{c}\text { C. V. } \\
(\%)\end{array}$} & \multirow{2}{*}{$\begin{array}{l}\text { Média } \\
\text { Geral }\end{array}$} \\
\hline & & $\begin{array}{l}\text { Épocas de } \\
\text { suspensão }\end{array}$ & $\begin{array}{c}\text { Reposição } \\
\text { de água }\end{array}$ & Resíduo & & \\
\hline & Graus de liberdade & 2 & 3 & 66 & & \\
\hline \multirow{7}{*}{ 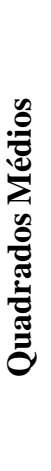 } & Altura da haste $(\mathrm{cm})$ & $4,450972(\mathrm{~ns})$ & $41,637917^{* *}$ & 4,796225 & 7,55 & 29,018 \\
\hline & Diâmetro da haste (mm) & $0,019106(\mathrm{~ns})$ & $1,113924^{* *}$ & 0,073789 & 8,52 & 3,17 \\
\hline & Número de folhas & $1,715000(\mathrm{~ns})$ & $111,530370^{* *}$ & 14,815438 & 14,40 & 26,733 \\
\hline & Número Inflorescência & $8,375000(\mathrm{~ns})$ & $611,199074^{* *}$ & 41,629209 & 27,50 & 23,458 \\
\hline & Diâmetro Inflorescência $(\mathrm{cm})$ & $0,174568^{*}$ & $18,147416^{* *}$ & 0,050513 & 3,25 & 6,916 \\
\hline & Massa fresca das raízes (g) & $1,608799(\mathrm{~ns})$ & $1,133604(\mathrm{~ns})$ & 2,137877 & 23,99 & 6,095 \\
\hline & Massa seca das raízes (g) & $0,022940(\mathrm{~ns})$ & $0,037191(\mathrm{~ns})$ & 0,045590 & 29,77 & 0,717 \\
\hline
\end{tabular}

Em que: ns não significativo;

* significativo a $5 \%$ de probabilidade pelo teste $\mathbf{F}$;

** significativo a $1 \%$ de probabilidade pelo teste $\mathbf{F}$.

Ciênc. agrotec., Lavras. V.27, n.3, p.658-664, maio/jun., 2003 


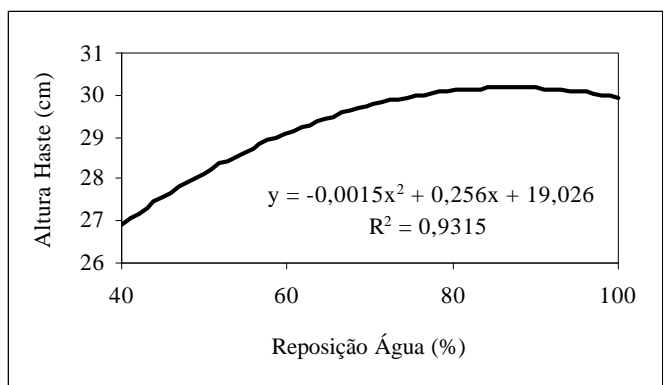

FIGURA 1 - Altura média das plantas de crisântemo cv. White Diamond, em função da reposição de água.

Com a aplicação do teste de média, tem-se melhor visualização de que não há diferença entre os tratamentos de $100 \%$ e $80 \%$ de reposição de água (Tabela 2). Observa-se que com o decréscimo dos níveis de reposição, a planta respondeu negativamente no seu desenvolvimento, ou seja, a altura da haste reduziu-se com aplicação do déficit hídrico.

Maior altura da haste para o tratamento com $80 \%$ de reposição possivelmente deve-se à casualização dos vasos. Alguns vasos que correspondiam a esse tratamento enquadraram-se em pontos onde provavelmente havia maior ventilação, favorecendo, assim, o desenvolvimento das plantas.

É importante para o cultivo de crisântemo em vasos que haja homogeneidade no tamanho das hastes. De acordo com Stringheta (1995), a altura ideal para as plantas de crisântemo em vaso está entre 20 a $25 \mathrm{~cm}$. Apesar de no experimento ter ocorrido médias superiores a essa faixa, (Tabela 2), a homoge- neidade de tamanho entre tratamentos manteve-se constante.

TABELA 2 - Altura da haste da cultura do crisântemo em função dos déficits hídricos aplicados.

\begin{tabular}{cc}
\hline Reposição de Água (\%) & Altura da haste (cm) \\
\hline 100 & $29,78 \mathrm{a}$ \\
80 & $30,57 \mathrm{a}$ \\
60 & $28,64 \mathrm{~b}$ \\
40 & $27,07 \mathrm{c}$ \\
\hline
\end{tabular}

Médias seguidas da mesma letra nas colunas não diferem entre si pelo teste Scott-Knott $5 \%$.

Irrigações com maiores níveis de reposição de água proporcionaram crisântemos com maiores diâmetros de haste e número de folhas, ou seja, para a reposição de $100 \%$ da água consumida, esses parâmetros foram maiores (Figura 2). Equações lineares foram ajustadas, expondo que, mantendo-se o meio de cultivo próximo à capacidade de campo, a cultura do crisântemo apresenta melhores rendimentos.

Observou-se para o diâmetro de haste que os menores níveis de reposição de água, principalmente a reposição de $40 \%$ da água consumida, proporcionaram menor rigidez das plantas, facilitando o tombamento das mesmas, sendo necessário tutorá-las.

Da mesma forma, para o tratamento com $40 \%$ de reposição, os vasos apresentaram pouco número de folhas e de menor tamanho, o que contribuiu para uma desvalorização comercial do produto.
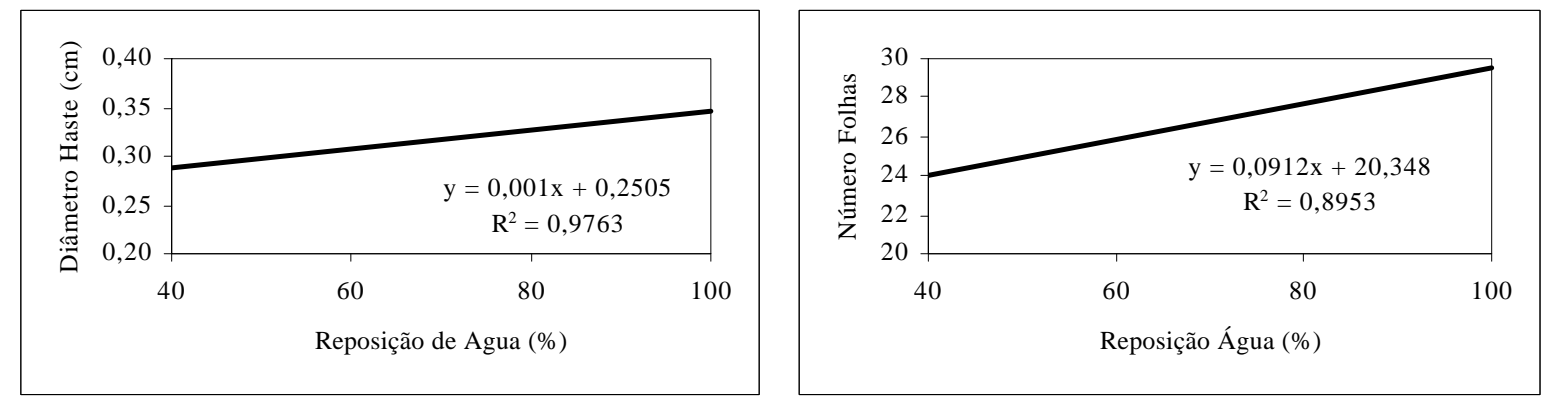

FIGURA 2 - Diâmetro da haste (mm) e número de folhas das plantas de crisântemo cv. White Diamond, em função dos diferentes níveis de reposição de água. 
Analisando o efeito da reposição de água, observou-se que, em geral, as maiores e melhores inflorescências, ou seja, as mais uniformes foram obtidas quando a reposição de água era de forma integral. Pela Figura 3, verifica-se a sensibilidade da cultura em relação aos diferentes níveis de reposição de água. Resultado semelhante foi observado por Dobashi et al. (1998) e Pereira et al. (2001).

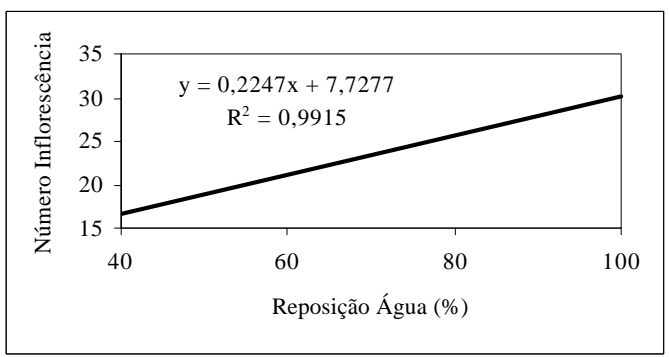

FIGURA 3 - Número de inflorescências desenvolvidas em plantas de crisântemo cv. White Diamond, em função dos diferentes níveis de reposição de água.

Entretanto, com o decréscimo dos níveis de reposição de água, houve favorecimento da abertura precoce dos botões florais. Para o tratamento com $40 \%$ e $60 \%$ de reposição, as inflorescências abriram aos 62 e aos 70 dias após o transplantio das mudas, respectivamente. Entretanto, para os tratamentos com $80 \%$ e $100 \%$ de reposição de água, as inflorescências abriram aos 83 e 91 dias após transplantio das mudas. Essa informação é uma importante ferramenta para o floricultor, pois, para períodos em que a demanda pelo produto aumenta, como por exemplo: Dia das Mães, dos Namorados, Finados e outros, se houver um atraso no ciclo da cultura, a indução da abertura das inflorescências poderá ser feita com a aplicação do déficit hídrico.

Houve, também, a influência das épocas de suspensão da adubação. Pela Tabela 3, observa-se que, com a suspensão da fertirrigação quando $20 \%$ e $40 \%$ das inflorescências apresentaram abertura das inflorescências, não houve diferença significativa quanto ao diâmetro da inflorescência. Já com a suspensão da adubação quando $60 \%$ das inflorescências estavam abertas, proporcionou-se maior diâmetro das inflorescências.
TABELA 3 - Diâmetro da inflorescência da cultura do crisântemo em função da época de suspensão da adubação.

\begin{tabular}{lc}
\hline Épocas de suspensão da adubação & $\begin{array}{c}\text { Diâmetro da } \\
\text { inflorescência } \\
\text { (cm) }\end{array}$ \\
\hline $60 \%$ da inflorescência abertas - (A) & 7,01 a \\
$40 \%$ da inflorescência abertas - (B) & 6,84 b \\
$20 \%$ da inflorescência abertas - (C) & 6,89 b \\
\hline
\end{tabular}

Médias seguidas da mesma letra nas colunas não diferem entre si pelo teste Scott-Knott $5 \%$.

Na prática, a adubação é cancelada, em média, 15 dias antes da colheita pelos produtores, o que corresponde ao tratamento $C$. Verifica-se pela Tabela 3 que há diferença entre as médias dos tratamentos $\mathrm{A}$ para $\mathrm{B}$ e $\mathrm{C}$ de apenas 0,12 a $0,17 \mathrm{~cm}$, não havendo grande diferença na prática, podendo o produtor economizar em adubos, em vez de conseguir pequena diferença em relação ao diâmetro das inflorescências.

Da mesma forma que para os demais parâmetros, a aplicação dos diferentes níveis de reposição de água interferiu significativamente no desenvolvimento da cultura. Com a reposição integral da água consumida, o diâmetro da inflorescência foi maior (Figura 4).

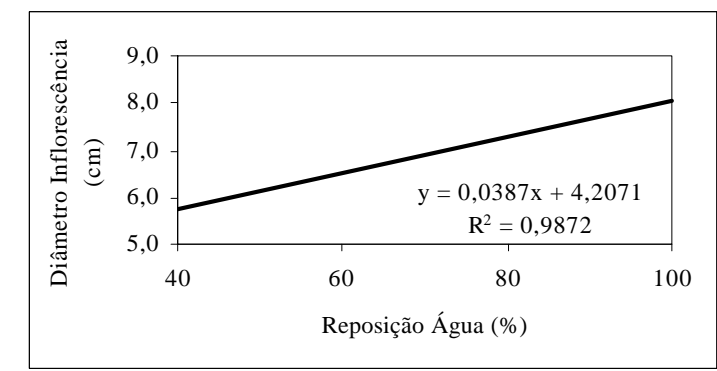

FIGURA 4 - Diâmetro da inflorescência das plantas de crisântemo cv. White Diamond, em função dos níveis de reposição de água.

Observou-se pela análise de variância dos dados de matérias fresca e seca das raízes que os tratamentos aplicados não apresentaram efeito significativo. Durante a remoção do sistema radicular, verificou-se que as plantas sujeitas a menores reposições de água

Ciênc. agrotec., Lavras. V.27, n.3, p.658-664, maio/jun., 2003 
apresentaram sistema radicular menos ramificado, mas com raízes mais grossas, enquanto aquelas cultivadas com maiores reposições de água apresentaram sistema radicular mais ramificado, porém, com raízes mais finas.

De acordo com Hoogenbomm et al. (1987), em condições de déficit hídrico, há maior expansão das raízes, devido ao secamento da superfície do solo, ou seja, o déficit hídrico estimula a expansão do sistema radicular para zonas mais profundas e úmidas do perfil do solo.

No final do experimento, as plantas foram classificadas de acordo com o Padrão de Qualidade IBRAFLOR. Pela Tabela 4, verifica-se a porcentagem de vasos pertencentes às classes $\mathrm{A}_{1}, \mathrm{~A}_{2} \mathrm{e} \mathrm{B}$, considerando as épocas de suspensão da fertirrigação quando $60 \%, 40 \%$ e $20 \%$ das inflorescências apresentavam-se abertas e os níveis de reposição de água aplicados.

Observa-se que houve maior porcentagem de crisântemos com a classe de qualidade $\mathrm{A}_{2}$, com a menor severidade do déficit hídrico, ou seja, com o aumento dos níveis de reposição de água. Os vasos apresentavam-se mais cheios e uniformes. Carvalho et al. (1999) verificaram o mesmo comportamento para a cultura do gladíolo, em que as melhores classes de qualidade, em todas as fases, foram obtidas aplicando-se menores déficits hídricos na cultura.

Observa-se que os tratamentos com $60 \%$ de reposição de água com $40 \%$ das inflorescências abertas apresentaram $16,67 \%$ dos vasos pertencente à classe $\mathrm{A}_{1}$. Provavelmente esse vaso foi disposto, durante a casualização, em local com boa ventilação no interior da estufa, favorecendo o desenvolvimento do crisântemo. Da mesma forma, foi o ocorrido com os vasos com tratamento de $80 \%$ da água consumida com $40 \%$ das inflorescências abertas.

Analisando-se a Tabela 3, verifica-se que a adubação interrompida, quando $60 \%$ das inflorescências estavam abertas, resultou em maior número de vasos pertencentes à classe de qualidade $\mathrm{A}_{2}$. É importante ressaltar que plantas com melhores classes de qualidade resultam em plantas com maior valor comercial.

Provavelmente a ausência de crisântemos com classificação $A_{1}$ é devida à temperatura, que auxiliou para o surgimento da mosca-minadora. Tal classificação recomenda plantas isentas de pragas, doenças e seus danos.

Observou-se que a classificação $A_{2}$ foi devida apenas à presença de alguns danos de praga na planta. Essas, no entanto, apresentaram-se vigorosas, com tamanho e diâmetro da haste dentro do padrão recomendado e vasos bem formados.

Contudo, algumas plantas que não apresentaram uniformidade e as dimensões fisiológicas fora do padrão recomendado obtiveram a classificação de qualidade B. Para essas plantas, observou-se, principalmente, menor diâmetro da haste, não dando sustentabilidade às plantas e altura da haste desuniforme.

TABELA 4 - Classificação dos vasos de crisântemo segundo as classes de qualidade em função dos níveis de reposição de água e das épocas de suspensão da adubação.

\begin{tabular}{lccccc}
\multirow{2}{*}{$\begin{array}{c}\text { Épocas de suspensão da } \\
\text { fertirrigação }\end{array}$} & $\begin{array}{c}\text { Classes de } \\
\text { qualidade }\end{array}$ & \multicolumn{4}{c}{ Níveis de reposição de água } \\
\cline { 3 - 6 } & & $\mathbf{1 0 0 \%}$ & $\mathbf{8 0 \%}$ & $\mathbf{6 0 \%}$ & $\mathbf{4 0 \%}$ \\
\hline \multirow{3}{*}{$60 \%$ inflorescências abertas } & $\mathrm{A}_{1}$ & - & - & - & - \\
& $\mathrm{A}_{2}$ & $83,33 \%$ & $66,67 \%$ & $66,67 \%$ & $50,00 \%$ \\
& $\mathrm{~B}$ & $16,67 \%$ & $33,33 \%$ & $33,33 \%$ & $50,00 \%$ \\
\hline \multirow{3}{*}{$40 \%$ inflorescências abertas } & $\mathrm{A}_{1}$ & - & - & $16,67 \%$ & - \\
& $\mathrm{A}_{2}$ & $66,67 \%$ & $83,33 \%$ & $66,67 \%$ & $33,33 \%$ \\
& $\mathrm{~B}$ & $33,33 \%$ & $16,67 \%$ & $16,67 \%$ & $66,67 \%$ \\
\hline \multirow{2}{*}{$20 \%$ inflorescências abertas } & $\mathrm{A}_{1}$ & - & - & - & - \\
& $\mathrm{A}_{2}$ & $83,33 \%$ & $66,67 \%$ & $66,67 \%$ & $33,33 \%$ \\
& $\mathrm{~B}$ & $16,67 \%$ & $33,33 \%$ & $33,33 \%$ & $66,67 \%$ \\
\hline
\end{tabular}




\section{CONCLUSÕES}

Com a reposição integral de água, obtiveram-se melhores qualidades quanto ao diâmetro da haste, número de folhas e inflorescência e diâmetro da inflorescência. O diâmetro da inflorescência foi influenciado pelas épocas de suspensão da adubação, verificando que as maiores inflorescências foram conseguidas pela suspensão da adubação quando $60 \%$ das inflorescências apresentavam-se abertas. As melhores classes de qualidade do crisântemo foram obtidas com a suspensão da adubação, quando $60 \%$ das inflorescências apresentavam-se abertas e com reposição integral da água consumida pela cultura.

\section{REFERÊNCIAS BIBLIOGRÁFICAS}

CARVALHO, J. de A.; HENRIAQUES, E. B.; MELLO, C. R.; PEREIRA, G. M.; ROCHA, A. Crescimento e produção do gladíolo (Gladiolus $x$ grandiflorum) cultivado com déficit hídrico nas diferentes fases fenológicas. In: CONGRESSO BRASILEIRO DE ENGENHARIA AGRÍCOLA, 28., 1999, Pelotas. Anais... Pelotas: Sociedade Brasileira de Engenharia Agrícola, 1999. 1 CD-ROM.

DOBASHI, A. M.; CARVALHO, J. de A.; PEREIRA, G. M.; RODRIGUES, L. dos S. Avaliação do crescimento da boca de leão (Antirrihimum majus) submetido a diferentes níveis de deficiência hídrica. In: CONGRESSO BRASILEIRO DE ENGENHARIA AGRÍCOLA, 27., 1998, Poços de Caldas. Anais... Poços de Caldas: Sociedade Brasileira de Engenharia Agrícola, 1998. v. 1, p. 100-102.

FERNANDES, A. L. T. Monitoramento da cultura do crisântemo em estufa através do uso de lisímetros e estação agrometereológica automatizados. 1996. 96 f. Dissertação (Mestrado em Irrigação e Drenagem) - Escola Superior de Agricultura “Luiz de Queiroz", Piracicaba.

FURLAN, R. A. Consumo de água pela cultura do crisântemo envasado, cultivar Puritan, sob condições de estufa. 1996. 96 f. Dissertação (Mestrado em Irrigação e Drenagem) - Escola Superior de Agricultura "Luiz de Queiroz", Piracicaba.

GRUSZYSNKI, C. Produção de Crisântemos. Disponível em: $<$ http://www.emater.tche.br/docs/artigos/crisa/crisant.ht m>. Acesso em: $16 \mathrm{dez} .2001$.

HOOGENBOMM, G.; HUCK, M. G.; PETERSON, C. M. Root growth rate of soybean as affected by drought stress. Agronomy Journal, Madison, v. 79, p. 597-614, 1987.

LIMA, A. M. L. P. Absorção de nutrientes e deficiência de macronutrientes e boro no crisântemo (Chrysanthemum morifoluim Ramat.) cultivar Goldem Polaris. 1987. 135 f. Dissertação (Mestrado em Solos e Nutrição de Plantas) - Escola Superior de Agricultura "Luiz de Queiroz", Piracicaba.

MATSUNAGA, M. Potencial da floricultura brasileira. Agroanalysis, Rio de Janeiro, v. 15, n. 9, p. 56, set. 1995.

MOTOS, J. R. (Coord.). Crisântemo em vaso. In: IBRAFLOR. Padrão IBRAFLOR de qualidade. Campinas: [s.n.], 2000. p. 9-10.

PEREIRA, J. R. D.; CARVALHO, J. de A.; HENRIAQUES, E. B.; PAIVA, P. D. de O.; PEREIRA, G. P. Crescimento e produção do gladíolo (Gladiolus $x$ grandiflorum) cultivado com déficit hídrico nas diferentes fases fenológicas. In: CONGRESSO DA PÓS-GRADUAÇÃO DA UFLA, 10., 2001, Lavras. Anais... Lavras: Associação de Pós-Graduandos da UFLA, 2001. 1 CD-ROM.

STRINGHETA, A. C. O. Avaliação de variedades de crisântemo em vaso, em substratos contendo composto de lixo urbano. 1995. $72 \mathrm{f}$. Dissertação (Mestrado em Fitotecnia) - Universidade Federal de Viçosa, Viçosa. 